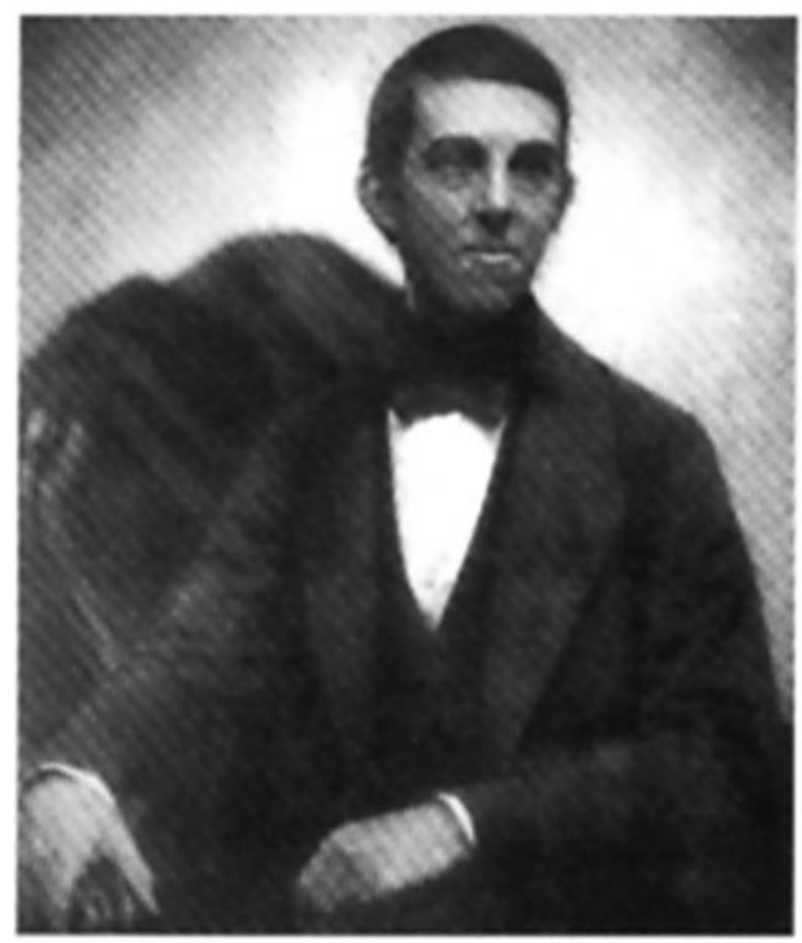

FIGURE 5. Dr. Oliver Wendell Holmes, from a daguerreotype, taken 1845-1850, belonging to James R. Chadwick. The letter from Dr. Holmes to Dr. Chadwick was found stuck in between this photograph and its backing. The photograph has been in Mrs. Gathright's family for several generations.
This letter gives us a personal glimpse of the triumph that Dr. Holmes experienced as he saw his treatises vindicated. His well-known humor is evident in the final sentence of his letter:

. . . I think I shrieked my warning louder

and longer than any of them, and I am pleased

to remember that I took my ground on the exist-

ing evidence before the little army of microbes

was marched up to support my position.

He surely would be pleased to know that his teachings and convictions bore fruit even then: our family tradition has it that my great-grandfather, Dr. Moseley, was the first doctor in Baltimore to tie up his whiskers when he attended to patients.

\section{REFERENCES}

1. Holmes OW. The contagiousness of puerperal fever. New England Quarterly Journal of Medical Surgery 1843;1:503$530 .^{*}$

2. Holmes OW. Puerperal Fever as a Private Pestilence. Boston, MA: Ticknor \& Fields; 1855 . $^{*}$

3. von Hebra F. Most important experiences about the etiology of puerperal fevers epidemic in birthing institutions. Zschr $k k$ Arzte zu Wien 1848;14(2):242-244. Translated in Infect Control 1982;3(6):478-479.

* Both of Holmes's publications were reprinted in Medical Classics 1936;1(3):211-243, 247- 268.

\title{
Transcript of Dr. Oliver Wendell Holmes' Letter to Dr. James R. Chadwick
}

A reproduction of the original letter may be found on pages 608-609

Dear Dr. Chadwick

296 Beacon St. May 8th 1893

You tell me that the President of the Gynecological Society, Dr. P . . . , proposes to make mention at the meeting of the Society next Tuesday of my early efforts to put a stop to the conveyance of the poison which produces puerperal fever from one lying-in woman to another by the practitioner to whose care she is entrusted.

It is just fifty years since my Essay on the Contagiousness of Puerperal Fever was published in the New England Journal of Medicine and Surgery. It had been previously read at a meeting of the Boston Society for Medical Improvement, at whose request it was given to the press. The periodical in which it appeared, though well conducted and promising well, died in its first year, having been seen by few readers, and supported by fewer subscribers. My warning and counsel had their effect, however, in our own community, as I have often been assured by competent authorities. The Essay attracted respectful notice abroad, as the names of Copland and Ramsbotham and the Fifth Annual Report of the Registrar General of England show sufficiently. Still, it was not read by some who might have profited by it. If Dr., afterwards Sir James Simpson had read the first rule I laid down he would not have left the record that after freely handling the diseased parts from an autopsy of a victim of puerperal fever his next four child-bed patients were affected with that disease.

I thought I had proved my point and set the question of the private pestilence, as I called it, at rest "for good and all." I thought I had laid down rules which promised to ensure the safety of the lying-in woman from disease and death carried to her unconsciously by her professional attendant. 